\section{$\underset{\text { hommes }}{\text { \& migrations }}$}

\section{Hommes \& migrations}

Revue française de référence sur les dynamiques

migratoires

$1303 \mid 2013$

Diasporas marocaines

\title{
Ilo Ilo
}

Film singapourien de Anthony Chen (2013)

\section{Anaïs Vincent}

\section{Q OpenEdition \\ 1 Journals}

\section{Édition électronique}

URL : http://journals.openedition.org/hommesmigrations/2601

DOI : 10.4000/hommesmigrations.2601

ISSN : 2262-3353

\section{Éditeur}

Musée national de l'histoire de l'immigration

\section{Édition imprimée}

Date de publication : 1 juillet 2013

Pagination : 200-201

ISBN : 978-2-919040-23-0

ISSN : $1142-852 X$

\section{Référence électronique}

Anaïs Vincent, « llo llo », Hommes \& migrations [En ligne], 1303 | 2013, mis en ligne le 23 janvier 2014, consulté le 22 septembre 2020. URL : http://journals.openedition.org/hommesmigrations/2601 ; DOI : https://doi.org/10.4000/hommesmigrations.2601

Ce document a été généré automatiquement le 22 septembre 2020.

Tous droits réservés 


\section{Ilo Ilo}

Film singapourien de Anthony Chen (2013)

\section{Anaïs Vincent}

1 Alors qu'Ilo Ilo du réalisateur Anthony Chen sortait en septembre dans les salles de l'Hexagone, il était sélectionné pour représenter Singapour dans la course à l'Oscar du meilleur film étranger. Destin prometteur pour ce premier long-métrage déjà lauréat de la Caméra d'or à Cannes en 2013.

2 Jiale est un petit garçon très turbulent, le fils unique d'une famille de la classe moyenne singapourienne. Sa mère, une employée de bureau, est enceinte de plusieurs mois et peine à accomplir sereinement les tâches domestiques. Elle décide alors d'embaucher une bonne pour l'aider. L'arrivée de Teresa, une jeune Philippine, va bouleverser leur quotidien alors que la crise économique de 1997 touche de plein fouet la cellule familiale. Pour réaliser ce film, le cinéaste a puisé dans ses souvenirs d'enfance. Il s'est promené dans le labyrinthe de sa mémoire et s'est souvenu de sa nourrice philippine originaire de la petite ville d'Iloilo.

3 En 1997, Singapour, un des quatre dragons asiatiques, connaît un afflux massif de capitaux étrangers, qui sont retirés par la suite. Ces mouvements fragilisent l'économie qui sombre dans la crise.

4 Dans son entreprise, la mère de Jiale est chargée de rédiger les lettres de licenciement qui se multiplient. Son père se retrouve au chômage après avoir perdu des sommes colossales en Bourse.

5 Malgré ce contexte morose, la ville-État reste une terre d'asile pour de nombreuses femmes philippines venues y chercher des revenus pour faire vivre leur famille restée au pays. Le vieillissement de la population singapourienne, dû à une politique de contrôle des naissances, nécessite une main-d'œuvre étrangère, tout particulièrement pour les tâches dédaignées par les Singapouriens comme le travail à domicile. Les Philippines sont les candidates idéales car elles parlent couramment l'anglais et sont réputées pour leur courage. Teresa est l'une d'entre elles. Le réalisateur raconte avec une froideur documentaire les conditions de vie déplorables de cette bonne. Dès son 
arrivée, elle se fait confisquer son passeport. Privée d'identité, elle est alors assignée à résidence. Sa religion, sa vie privée et jusqu'à son humanité sont rejetées.

6 En plus de ce travail harassant, Teresa décide de devenir coiffeuse dans un salon tenu par une Philippine. Elle gagne au noir quatre dollars de l'heure. Elle sait que c'est illégal et qu'elle risque gros en enfreignant les lois de ce pays autoritaire. Mais sa situation ne lui laisse pas le choix.

7 Selon un rapport d'Human Right Watch à Singapour, de 1995 à 2007, environ 147 travailleurs domestiques étrangers sont morts pendant leur travail. Ce chiffre comprend les accidents du travail et les suicides. La vie échappe à Teresa comme le bâton auquel elle suspend le linge pour le faire sécher. Cette scène terrible et admirablement réalisée révèle la détresse de cette femme, métaphore de celle de toute une communauté exploitée. Cet esclavage moderne est terrifiant et n'existe pas seulement à Singapour...

8 En traitant par la fiction ce sujet brûlant, le jeune cinéaste nous questionne sur le statut de ces femmes exilées. S'il dépeint un tableau très sombre de la société singapourienne des années 1990, il ne bascule pourtant jamais vers un misérabilisme larmoyant. 